Revista Brasileira de Higiene e Sanidade Animal Brazilian Journal of Hygiene and Animal Sanity ISSN: 1981-2965

\title{
Climatização especifica de maternidade suína: avaliação etológica de fêmeas lactantes
}

Specific climatization of swine maternity: ethological evaluation of lactating females

\author{
Gisele Dela Ricci ${ }^{1}$, Dirlei Antônio Berto ${ }^{2}$, Osmar Dalla , Rafael Teixeira de Sousa ${ }^{4}$, \\ Elder Tonon ${ }^{5}$, Cristiane Gonçalves Titto ${ }^{6}$.
}

Resumo: O experimento foi realizado durante o verão na UNESP campus Botucatu. Foram utilizadas oito fêmeas da raça Landrace e Large White, distribuídas aleatoriamente de acordo com a ordem de parição. O comportamento foi avaliado na primeira semana de lactação nos períodos da manhã, tarde e noite. O ambiente da maternidade foi vedado por lona plástica. Para a climatização foram utilizados seis ventiladores e dois aspersores de água no telhado. As temperaturas ambientais foram monitoradas através de termômetros de bulbo seco/úmido e globo negro ( $\mathrm{Tg}$ ) com leituras a cada cinco minutos, no decorrer dos cinco dias. A temperatura corporal dos animais foi medida com o auxílio do termômetro digital. Foram comparados os ambientes com enriquecimento e controle, sendo a análise do comportamento das fêmeas realizada com o auxílio de um etograma. O comportamento dos animais foi avaliado através do teste de Qui-Quadrado $\left(X^{2}\right)$, através do procedimento FREQ do SAS versão 9.1.2 (SAS Inst. Inc., Cary, NC). Os comportamentos lúdicos, estereotipados, ofego, alimentação, consumo de água e movimentação diferiram estaticamente entre os tratamentos, com melhora significativa do bem-estar das matrizes no ambiente climatizado, principalmente pela diminuição da temperatura ambiental, onde as médias de temperatura na área climatizada foram de 17 e $18^{\circ} \mathrm{C}$ e $32,34^{\circ} \mathrm{C}$ e controle, com menores frequências respiratórias, com médias de 38 e 79 batimentos por minuto e melhoria do ofego nos três períodos. Conclui-se que a utilização de ventiladores internamente e aspersores de água no telhado externamente, melhorou o conforto térmico e o bem-estar das fêmeas suínas paridas.

Termos para indexação: água, bem-estar, observação, suinocultura, ventiladores

Abstract The experiment was carried out during the summer at UNESP in Botucatu. Eight females swines of the Landrace and Large White breed were randomly assigned according to the order of calving. The behavior was evaluated in the first week of lactation in the morning, afternoon and night periods. The environment of the maternity was sealed by plastic canvas. For the climatization were used six fans and two water sprinklers on the roof. Environmental temperatures were monitored by dry / wet bulb thermometers and black globe (Tg) with readings every five minutes, over the course of five days. The body temperature of the animals was measured with the aid of the digital thermometer. The environments with enrichment and control were compared, and the behavior of the females was performed with the aid of an etogram. The behavior of the animals was evaluated using the chi-square test $\left(\mathrm{X}^{2}\right)$, using the FREQ procedure of SAS version 9.1.2 (SAS Inst. Inc., Cary, NC). Litter, stereotyped, breathing, feeding, water consumption and movement differed statically among treatments, with a significant improvement in the well-being of the females in the climatization environment, mainly due to the decrease in the ambient temperature, where the 
temperature averages in the climatized area were of 17 and $18^{\circ} \mathrm{C}$ and $32,34^{\circ} \mathrm{C}$ and control, with lower respiratory frequencies, with averages of 38 and 79 beats per minute and improved breathing in the three periods. It is concluded that the use of ventilators internally and sprinklers of water on the roof externally, improved the thermal comfort and the welfare of the swine.

Index Terms: water, welfare, observation, swine, fans

\footnotetext{
Autor para correspondência:

Recebido em 20.02.2018. Aceito em 30.06.2018

http://dx.doi.org/10.5935/1981-2965.20180019

${ }^{1}$ Universidade de São Paulo, campus Fernando Costa, Pirassununga, São Paulo.E.Mail: giseledelaricci@usp.br

${ }^{2}$ Universidade Estadual Paulista, Botucatu, São Paulo.E.Mail: dirleiberto@fmvz.unesp.br

${ }^{3}$ Embrapa- Suínos e Aves, Concórdia, Santa Catarina.E. Mail: osmar.dallacosta@embrapa.br

4 Faculdade de Medicina Veterinária e Zootecnia, Pirassununga, São Paulo.E. Mail: rafaelvnp@usp.br

${ }^{5}$ Universidade de São Paulo, campus Fernando Costa, Pirassununga, São Paulo. E. mail: el.tonon@ hotmail.com

${ }^{6}$ Universidade de São Paulo, campus Fernando Costa, Pirassununga, São Paulo. E. Mail: crisgtitto@usp.br
}

\section{Introdução}

Em sistemas de produção de carne suína, o fornecimento de um ambiente térmico adequado nas diferentes fases de produção é primordial tanto para a obtenção de índices zootécnicos satisfatórios quanto para a promoção do bem-estar animal. Nesse aspecto, o grande desafio é atender a determinação das exigências de bem-estar pelos consumidores, sem comprometer os índices produtivos, a partir de ferramentas inovadoras (BORGES et al., 2010). O bem-estar em suínos é avaliado a partir de medidas comportamentais e indicadores fisiológicos. Sendo o primeiro, baseado na ocorrência de comportamentos diferentes do natural, enquanto o segundo, em variações nos níveis sanguíneos, batimentos cardíacos, temperatura corporal e frequência respiratória (ZANELLA, 1995).

A maternidade apresenta grande desafio em relação a regulação de temperatura uma vez que na maior parte do ano há altas temperaturas em que as porcas estão expostas e os leitões estão normalmente em um espaço reservado para eles, que pode ser aquecido artificialmente, os escamoteadores (CAMPOS, 2008). O suíno não possui glândulas sudoríparas em número suficiente para realizar sudorese significativa, não possuindo este mecanismo para se proteger das altas 
temperaturas, utilizando a ofegação e mudanças comportamentais para isso. Deste modo, a troca de calor do suíno ocorre na forma de calor sensível (condução, convecção e radiação) e latente (evaporação), sendo a eficiência dessa troca influenciada pela temperatura, velocidade e umidade relativa do ar (PERDOMO, 1999; BORTOLOZZO, 2011).

Em matrizes suínas, o estresse por calor, reduz grandemente a quantidade e o tempo de ingestão de alimentos, caracterizando alteração do comportamento ingestivo,

com consequentes redução no desempenho das fêmeas e de suas leitegadas (QUINIOU, et. al, 2000). Comportamentos diferenciados como estereotipias podem ser notados em matrizes suínas submetidas a estresse calórico. Este comportamento é uma forma de anormalidade, definido como movimentos repetitivos que ocupam grande parte do tempo do animal (MANSON, 1991). Para os suínos, as estereotipias mais comuns são a mastigação das gaiolas, madeiras, bebedouros, comedouro e instalações, enrolar a língua e falsa mastigação (ZANELLA, 1995).

A mortalidade na maternidade representa a maior causa de perdas na suinocultura (ABRAHÃO et al., 2004).
Sistemas como nebulização, ventilação, ar condicionado e resfriamento evaporativo são métodos que previnem o estresse calórico, apesar de a temperatura corporal não ser influenciada pelos resfriadores, os métodos são considerados benéficos para a melhora do conforto animal (QUINIOU, 2000). Suínos submetidos a temperaturas acima da sua zona de termo neutralidade utilizam de mecanismos fisiológicos, como ofegação, para a redução da temperatura corporal (Zanella, 1995). Dentro desse contexto, objetivou-se com este estudo avaliar o comportamento de matrizes suínas em ambiente de maternidade com e sem climatização.

\section{Material e Métodos}

O experimento foi realizado durante os meses do verão de janeiro a março, no setor de suinocultura da Faculdade de Medicina Veterinária e Zootecnia, UNESP campus de Botucatu. Foram utilizadas oito matrizes da raça Landrace e Large White, distribuídas aleatoriamente de acordo com a ordem de parição $\left(1^{\circ}, 2^{\circ}, \quad 3^{\circ} \mathrm{e} \geq 4^{\circ}\right) . \quad \mathrm{O}$ comportamento das matrizes foi avaliado na primeira semana de lactação nos períodos da manhã: das seis às oito horas, tarde: das doze às quatorze horas e a noite: das dezoito as vinte horas), com intervalos de cinco minutos entre as observações. As fêmeas foram mantidas em celas de parição e o manejo da granja não foi 
alterado. $\mathrm{O}$ ambiente da maternidade foi vedado, permanecendo quatro celas do lado esquerdo e quatro do lado direito, vedada por lona plástica para melhor eficácia dos aparelhos de climatização em relação a área controle. Para a climatização foram utilizados seis ventiladores e dois aspersores de água no telhado. Dos ventiladores, dois estavam localizados no telhado e outros quatro ventiladores de coluna (modelo Q500C e $1150 \mathrm{rpm}$ ) nas laterais da sala, na frente e na altura da cabeça do animal em sentido giratório. Os aspersores eram fixados no telhado e acionados no momento das observações.

As temperaturas ambientais foram monitoradas através de termômetros de bulbo seco/úmido e globo negro (Tg) com leituras a cada cinco minutos, dentro dos três períodos do dia, no decorrer dos cinco dias. A temperatura corporal dos animais foi medida com o auxílio do termômetro de infravermelho.

Foram comparados os ambientes com enriquecimento e controle, sendo a análise do comportamento das matrizes realizada com o auxílio de um etograma, onde foram avaliados os comportamentos lúdicos, estereotipados, ofego, ócio, interações sociais com leitões, alimentar, consumo de água, movimentação e de micção de acordo com a Tabela 1. O comportamento dos animais foi avaliado através do teste de Qui-Quadrado $\left(X^{2}\right)$, através do procedimento FREQ do SAS versão 9.1.2 para Windows (SAS Inst. Inc., Cary, NC).

Tabela 1. Descrição dos comportamentos avaliados.

\begin{tabular}{|c|c|}
\hline Comportamentos & Descriçãa \\
\hline Lúdico & $\begin{array}{c}\text { Comportamento caracterizado por brincadeiras, geralmente } \\
\text { em movimentos circulares dentro da baia. }\end{array}$ \\
\hline Estereotipado & $\begin{array}{c}\text { Comportamento compensatório apresentado através de } \\
\text { atividades repetitivas. }\end{array}$ \\
\hline Procurar o bebedouro & $\begin{array}{l}\text { Ato em que o animal realiza o acionamento do bebedouro } \\
\text { consumindo água. }\end{array}$ \\
\hline Procurar o comedouro & $\begin{array}{l}\text { Ato em que o animal se direciona ao comedouro, ingerindo } \\
\text { alimento. }\end{array}$ \\
\hline Ócio & $\begin{array}{l}\text { Foi considerado ócio quando os leitões estavam dormindo, } \\
\text { deitados, sentados e em pé. }\end{array}$ \\
\hline Ofego & Aumento da frequência respiratória \\
\hline Interações sociais & $\begin{array}{l}\text { Animal cheirando um ao outro sem manifestar } \\
\text { comportamento agressivo ou de vícios }\end{array}$ \\
\hline Eliminação & Excreção de urina e fezes. \\
\hline Movimentação & $\begin{array}{l}\text { Animais andando sem sinal de exploração do ambiente, ou } \\
\text { seja, fuçando. }\end{array}$ \\
\hline
\end{tabular}




\section{Resultados e Discussões}

Os comportamentos lúdicos, estereotipados, ofego, alimentação, consumo de água e movimentação diferiram estaticamente entre os tratamentos $(\mathrm{P}<0,01)$ com melhora significativa do bem-estar das matrizes no ambiente climatizado, principalmente pela diminuição da temperatura ambiental, onde as médias de temperatura na área climatizada foram de 17 e $18^{\circ} \mathrm{C}$ e $32,34^{\circ} \mathrm{C}(\mathrm{P}<0,01)$ e no controle, com menores frequências respiratórias, com médias de 38 e 79 batimentos por minuto $(\mathrm{P}<0,01)$ e melhoria do ofego nos três períodos $(\mathrm{P}<0,01)$, Tabela 2.

Tabela 2. Variações de comportamento das fêmeas suínas entre os tratamentos avaliados.

\begin{tabular}{cccc}
\hline \multirow{2}{*}{ Comportamento } & \multicolumn{2}{c}{ Enriquecimento Ambiental } & \multirow{2}{*}{ Probabilidade $>\mathrm{X}^{2}$} \\
\cline { 2 - 3 } & Climatizada & Controle & $<0,01$ \\
\hline Lúdico & $61,88 \%$ & $38,12 \%$ & $<0,01$ \\
Estereotipado & $33,06 \%$ & $66,94 \%$ & 0,16 \\
Ócio & $52,41 \%$ & $47,59 \%$ & 0,36 \\
Interação social & $51,49 \%$ & $48,51 \%$ & $<0,01$ \\
Procura pelo comedouro & $72,53 \%$ & $27,47 \%$ & $<0,01$ \\
Procura pelo bebedouro & $72,28 \%$ & $27,72 \%$ & $<0,01$ \\
Movimentação & $73,27 \%$ & $26,73 \%$ & $<0,01$ \\
Ofego & $18,42 \%$ & $81,58 \%$ & 0,54 \\
Micção & $52,35 \%$ & $47,65 \%$ & \\
\hline
\end{tabular}

Neste estudo, no ambiente climatizado, as fêmeas procuraram o cocho e o bebedouro com maior frequência quando comparado a matrizes no ambiente controle $(\mathrm{P}<0,01)$, Tabela 2 . Matrizes suínas em estresse calórico apresentam alterações no comportamento ingestivo, com diminuição no consumo de ração, no tempo de ingestão dos alimentos e no tamanho da refeição (Quiniou et al., 2000; Renaudeau et al., 2003), reduzindo o pico de consumo e aumentando a ingestão de alimentos nas horas com menores temperaturas do dia (GOURDINE et al., 2006). A atividade de eliminação não diferiu entre os tratamentos, podendo ser explicado pelo fato de que as fêmeas permaneciam maior tempo em decúbito no ambiente climatizado, pelo maior conforto $(\mathrm{P}>0,05)$.

Suínos confinados em baias por períodos longos, apresentam comportamentos estereotipados, outros se tornam inativos e ou não responsivos (BROOM, 1981). Neste estudo, foram observados movimentos de morder as grades das gaiolas, repetidamente, nos três períodos avaliados $(\mathrm{P}<0,01)$. No entanto, na instalação controle, este comportamento foi avaliado em maior número de repetições ( $\mathrm{P}<0,01)$, Tabela 2, podendo ser explicado pelo menor conforto térmico das fêmeas e pelo confinamento em gaiolas, enfatizando a importância da maternidade coletiva para 
matrizes suínas.

A interação social entre fêmeas suínas confinadas em gaiolas e lactentes é reduzida devido ao espaço demasiadamente diminuído. Neste estudo, notou-se que os leitões se direcionam a frente da gaiola, ao fucinho da mãe, buscando interações positivas, de afeto $(\mathrm{P}>0,05)$.

Em relação ao comportamento de ócio, pela presença limite das gaiolas, as porcas tendem a permanecer em inatividade, independente da climatização em que são submetidas $\quad(\mathrm{P}>0,05) . \quad \mathrm{Na}$ análise dos comportamentos em relação aos períodos avaliados, apenas o comportamento lúdico apresentou diferença significativa, com maiores apresentações deste comportamento no período da manhã $(\mathrm{P}<0,01)$. O período da manhã, além de apresentar temperaturas amenas, ainda é o

\section{Referências Bibliográficas}

1. ABRAHÃO, A.A.F.; VIANNA, W.L.; CARVALHO, L. F. O. S.; MORETTI, A. S. Causas de mortalidade de leitões neonatos em sistema de produção de suínos. Brazilian Journal of Veterinary Research and Animal Science, v. 41, n. 2, p. 86-91, 2004.

2. BORTOLOZZO, F. P, et al. Estratégias de redução do catabolismo lactacional manejando a ambiência na maternidade. MEATWORD: O Mega Portal da Produção de carne Brasileira [site]. 20 set. 2011. Disponível em: 21 nov de 2017

3. BORGES, G.; MIRANDA, K.O.S.; RODRIGUES, V.C.; RISI, N. Uso da geoestatística para avaliar a captação automática dos níveis de pressão sonora em instalações de creche para suínos. Engenharia Agrícola, v.30, n. 3, p. 377-385, 2010.

4. BROOM, D.M. Animal welfare: concepts and measurement. Journal of Animal Science, v.69, p.4167-4175, 1991. período em que o manejo de limpeza e reposição da cama é realizado, e os animais tendem a explorar e brincar mais nestes períodos.

O comportamento lúdico apresentou baixa frequência de apresentação, demonstrando que o bem-estar é pobre (Broom; Molento, 2004), sendo considerado como uma atividade natural dos suínos (DONALDSON et al., 2002).

\section{Conclusões}

A utilização de ventiladores internamente e aspersores de água no telhado externamente, melhorou o conforto térmico e o bem-estar das fêmeas suínas paridas. Ademais, esses achados mostram a importância da observação do comportamento animal como ferramenta no entendimento e atendimento das questões relacionadas ao bem-estar animal em sistemas de produção suinícolas em condições tropicais.

5. BROOM, D.M.; MOLENTO, C.F.M. Bem-estar animal: conceitos e questões relacionadas Revisão. Archives of Veterinary Science, v.9, n.2, p.1-11, 2004.

6. CAMPOS, J. A. Ambiente térmico e desempenho de suínos em dois modelos de maternidade e creche, Viçosa, p. 187-193, mai/jun. 2008.

7. DONALDSON, T.M.; NEWBERRY, R.C.; SPINKA, M.; CLOUTIER, S. Effects of early play experience on play behaviour of piglets after weaning. Applied Animal Behaviour Science, v. 79, p. 221-231, 2002.

8. GOURDINE, J.L.; BIDANEL, J.P.; NOBLET, J. et al. Effects of breed and season on performance of lactating sows in a tropical humid climate. Journal of Animal Science, Minnesota, v.84, n.2, p.360-369, 2006. 
9. MANSON, G.J. Stereotypies: a critical review.

Animal Behaviour, v. 41, p.1015- 1037, 1991.

10. PERDOMO, C. C, et al. Efeito da ventilação natural e mecânica sobre o desempenho de porcas em lactação. Brasília, v. 34, n. 4, p. 691-699, abr. 1999.

11. QUINIOU, N.; RENAUDEAU, D.; DUBOIS, S.; NOBLET. J. Effect of diurnally fluctuating high ambient temperatures on performance and feeding behaviour of multiparous lactating sows. Animal Science, 71: 571-57, 2000.

12. RENAUDEAU, D.; ANAÍS, C.; NOBLET, J. Effects of dietary fiber on performance of multiparous lactating sows in a tropical climate. Journal of Animal Science, v.81, n.3, p.717-725, 2003.

13. ZANELLA. A.J. Indicadores fisiológicos e comportamentais do bem-estar animal. A Hora Veterinária, v.14, n.83, p.47-52, 1995. 